\title{
Future Challenges for School Leaders in Implementing the Concept of Learning Organizations in Malaysian Schools: Experts' Opinions
}

\author{
https://doi.org/10.3991/ijac.v13i1.12635 \\ Rosnah Ishak \\ Sultan Idris Education University, Perak, Malaysia \\ rosnah.ishakefpe.upsi.edu.my
}

\begin{abstract}
Based on the idea of learning organizations, schools should be a place for everyone to learn, including teachers and the principals themselves. Hence, school leaders should be prepared to face various possibilities in implementing the concept of learning organizations in school. This paper discussion about a study aims to identify future challenges for school principals as leaders in learning organizations. A total of eight school principals have been appointed to a panel of experts and involved in a focus group discussion. The results from qualitative data analysis show that there are seven main elements forecast to be the challenges for school leaders in developing their schools as learning organizations in future. The implications of the study suggest that school leaders apply a variety of leadership skills as a result of their learning to overcome those challenges.
\end{abstract}

Keywords - Learning organization, school leaders, future challenges, Malaysia

\section{$1 \quad$ Introduction}

Leadership challenges in educational institutions at the primary, secondary and tertiary levels are always in tandem with the changing environment, technology and economy. These changes also led to the changing role and responsibility of individuals in the leadership position [5]. In learning organizations where everyone learns, school leaders are also no exception. Leaders need to reflect, discuss, experiment and learn [2]. In addition, school leaders should also be the catalyst for professional learning of teachers and staff under their leadership [12]. Hence, school leaders have to take on new challenges to obviate the conservative thinking that school is a place where only the students learn. They play the most important role in the process of transforming the school into a learning community [17]. Building a learning organization should become a strategy for the organizational development and should become leaders' responsibility, it is not an option [14]. The leader is the one who should take actions first to support a learning organization. A transition shift from a transactional and transformative leader to a learning leader [2] means that they will be involved in learning, adjust to change and encourage innovation in schools. Moreover, in learning 
organizations, leaders need to develop a learning team, which will help them to carry out extensive and deep reform and get overall strength from the team [1]. It is a new role for a "chief-learning leader" [18], which is an outstanding feature in the organization. As such, the leadership role will become apparently challenging.

The latest research in this field covers all sorts of challenges in leading a learning organization such as pedagogical challenges [10], learning capabilities [4], generational diversity and social network [6], putting learning into practice [18], knowledge management [9] and culture [8]. Other factors will continuously add to the list because organizational environments keep changing rapidly in this knowledge era. Nonetheless, the leaders need to follow the pace to put them on track with the new opportunities and prepare themselves with the strategies to overcome those challenges and gain the competitive edge.

\section{Research Background}

\subsection{Research problem}

According to Retna and $\mathrm{Ng}$ [16], the principal role as the school leader is to provide understanding to teachers to accept the learning philosophy. In addition, school leaders should also be able to manage changes during the transformation process [7,13]. Throughout the transformation process, school leaders also have been entrusted with the responsibility to ensure that leadership and learning in schools is transformed to reflect a new paradigm [2] which provides the space and opportunity for teachers' individual professional understandings and aspirations to be acknowledged and built on [11]. Therefore, becoming a leader in a learning organization is an agonizing task. School leaders face numerous challenges because of various factors and the complex school organization and network. School leaders need some guidelines on what challenges they need to surmount especially when they are just being appointed to the position or on the condition that they want to attain their task effectively. Hence, this study aims to identify the future challenges for school principals as leaders in learning organizations. Eight school leaders who have undertaken school transformation efforts into learning organizations were involved in the focus group interview. This paper expected to open more discussion and help school leaders to be more prepared in facing challenges developing their schools as learning organizations in the future.

\subsection{Research focus}

The research focus is to forecast future challenges in implementing the concept of learning organizations in school context. 


\section{$3 \quad$ Methodology}

\subsection{Research design}

This study was a qualitative approach research using focus group discussion. The respondents were selected using a purposive sampling method based on predefined criteria as panel of experts. Discussions were recorded manually and using a voice recorder. Transcribed discussion data was validated by all the respondents with added information here and there. Data were extracted into main theme and subtheme to signify the main challenges and explaining challenges.

\subsection{Research Sample}

All the respondents were school principals who:

i) Have been involved in school administration for more than 10 years (including head of department and senior assistant teacher).

ii) Are engaging in transforming schools into learning communities.

iii) Have the knowledge about the concepts of learning organizations and organizational learning. Due to the difficulty in identifying the respondents, the method of snowball sampling was used. Some identifiable respondents provided names of several other respondents who met the specific criteria. Via this method, 20 respondents have been listed. They were contacted via email and phone. Of these, only eight respondents could spend time in the focus group meeting.

\section{$4 \quad$ Data Collection}

In the focus group meeting, a method of brainstorming was used to collect information. Respondents were given an open-ended question for discussion: what are the challenges they will face in the future in transforming their school into a learning organization? The role of the researcher in the discussion was to facilitate and initiate the discussion. The discussions were recorded using the voice recorder and the important details of the discussion were recorded in written forms. Upon the discussion, the researcher used a form to record the occurrence of certain words uttered by the experts. The frequency of some words being used or expressed by the experts were also recorded.

Discussion data was transcribed, coded and then sent back to all respondents for validation. Content analysis was used to find the emerging patterns of theme and subtheme. Based on the frequency of the occurrence of any word referring to the challenges, it will be listed as a theme or subtheme of the projected challenges raised up by the experts. Then, a tree chart was constructed to illustrate the overall findings of the research. Subsequently, the tree chart that contained the theme and subtheme of the challenges was then sent back again to the experts to be validated. 
Using frequency analysis, generation differences have been uttered 21 times, resource provision has been identified 17 times in the discussion, ever-changing policy in education was stated 43 times, rapid technological changes occurred 26 times, delay in obtaining expected results was uttered 13 times. Meanwhile, knowledge management was used 9 times and difficulties in forecasting the future of education in Malaysia has been identified 32 times in the discussion. Words that appeared not more than 5 times were eliminated from the list. Some of the experts do not use the exact specific word so the researcher had to reconfirm the actual meaning of the words used by them. A tree chart was constructed based on the seven subthemes. The researcher put them in two big themes suggested by five of the experts. The tree chart looked like this:

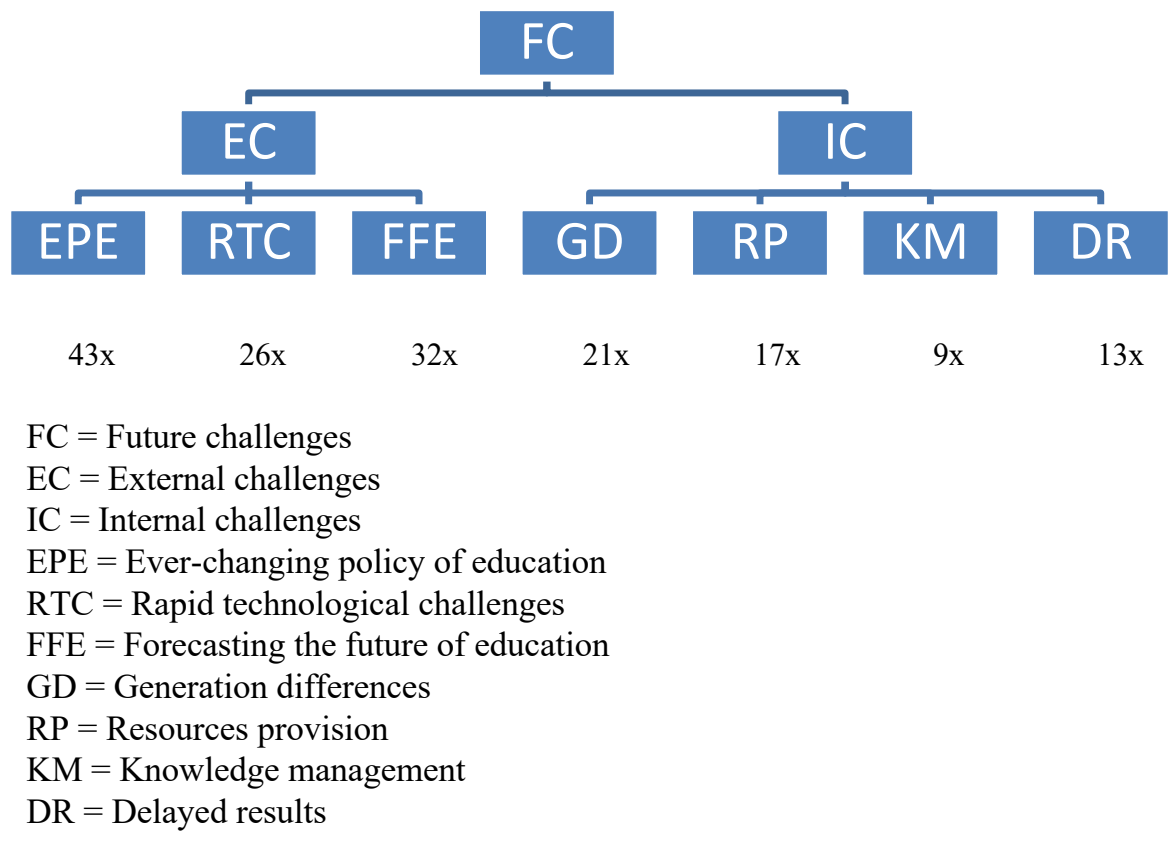

\section{$5 \quad$ Findings}

The study found seven future challenges in the leadership of learning organizations. These challenges have been classified into two main categories, namely internal challenges and external challenges. Internal challenges refer to challenges in a particular school. External challenges refer to the challenges that come from outside of the school.

\subsection{Internal challenge}

There are four internal challenges found in the study which are challenges in terms of generation differences, resources provision, knowledge management and the delay in obtaining the expected results. 
The first challenge is the generation differences. In the ' $90 \mathrm{~s}$, most of the workforce was from the Generation X category and Baby Boomers. But now Generation Y has begun to enter the job sector. The earliest Generation Y members have been in service for more than ten years now and are about 35 years old. The differences in the generation of this workforce has changed the notion of the teacher's work. The Generation Y workforce, also known as the Millennials, brings with them some characteristics and ways of working that are quite different from the previous generation. Leaders of learning organizations need to learn to recognize and understand the characteristics and ways of working of each generation so that optimum capabilities can be obtained from every staff member.

The second internal challenge is in terms of resource provision. The provision of resources here means providing a workforce that can meet the needs of the school and other resources required by the learning organization. It really deals with the difference in the generation of the workforce that has been discussed earlier. Past generations are described as good followers. If they were appointed to teach a subject that was not of their choosing or directed to do any task, the teacher would obey the order. Generation $\mathrm{Y}$ teachers are likely not like that. They need justification for every instruction: why they have to do that and for what reason they need to do the task given and comply with the instructions. They have various potential but prefer to do what they love. This attitude and characteristic causes some management agenda to be difficult to be implemented. In addition, the provision of learning resources will also be a challenge to future leadership in relation to different learning habits between the two generations. Generation $\mathrm{X}$ learns through courses and reading books physically, while Generation Y learns through online courses, YouTube, reading e-books and so on.

The third challenge is in managing the knowledge in the school. The learning organization school requires its leader to recognize the expertise of each teacher and the staff. The ability and capabilities of the staff are usually more easily determined based on their position and job description. However, teachers have diverse expertise based on their teaching experience in previous schools as well as their professional qualifications. Knowledge management skills require school leaders to use certain tools or methods to gain knowledge, and store, retrieve, use and create new knowledge within the organization. In addition, knowledge management skills can prevent brain-drain when the teacher or the other staff retires or is transferred to another school.

The next challenge is the challenge in terms of the delay in achieving the results. Teacher learning brings about many innovations. However, not all learning can generate new knowledge fast. For example, innovation in pedagogy or school programs can sometimes take up to two or three years to obtain the results. The delay in attaining the expected results will cause school leaders to feel depressed as they need to show immediate results as evidence of their leadership capabilities. This challenge is acknowledged by all respondents as the most difficult challenge as it involves various stakeholders of the school. 


\subsection{External challenges}

There are three major external challenges found in the study, listed as the everchanging policy of education, the rapid technological challenges and the difficulties in forecasting the future of education in Malaysia.

The first external challenge in leading a learning organization is the challenge of ever-changing educational policies. Education is very dynamic because some of the educational goals themselves are to supply labour to the job market. Thus, education is provided according to the market requirements. However, the Ministry of Education, Malaysia, as a responsible body in providing basic education to students, should be firm with a policy that focuses more on educating the students. Since the beginning of the 21st century, Malaysian schools have been involved with various radical changes that witnessed various parties interfering with the education. This causes the teachers to lose focus on their essential task of teaching and learning. Teachers also complained about the lack of time to learn as much of the tasks had to be completed fast. Most of the time, the activities that can be utilized for their learning have become wasteful because they are unable to get benefits from such activities for learning purposes. Thus, leaders in learning organizations face challenges to help teachers integrate learning into each task so that each teacher activity becomes meaningful for their learning.

The second challenge is in terms of new technology that is fast developing. New technology, especially information and communication (ICT), helps the school staff, especially teachers, with their learning. With the help of state-of-the-art technology, teachers can access information easily. However, the learning process is not that easy. The process of learning and the process of obtaining information are two things that are closely related but not the same. The ease of obtaining information does not necessarily give a person benefit in terms of learning. Mastering certain fields of knowledge takes years. Therefore, leaders of learning organizations face challenges to ensure teachers are more interested in learning with the help of new and current technology as an enabler.

The next challenge is a challenge in terms of difficulty in anticipation of future education. With rapid changes in education policies, the change in the status of teachers' educational institutions (e.g., upgrading the teacher training college to teacher education institutes), changes in school assessment systems and public examinations, increasing the retirement age limit from 55 to 60 years, changing the primary and secondary schools curriculum, introducing new initiatives and approaches frequently, the future of the Malaysian education system is becoming increasingly difficult to expect. Faced with these challenges, some teachers take action to add value to their services by continuing their education to the next level. However, many teachers face this uncertainty by taking action as "wait and see what will happen next". In learning organizations, individuals who cannot improve their service quality either through formal, informal or non-formal learning will not contribute to organizational excellence. Difficulty in forecasting the future of education should not weaken the teachers' passion in learning. It should not become a catalyst for hindering the teacher to remain competitive. Hence, leaders of learning organizations face the challenge in ensuring that teachers do not place themselves in a comfortable zone in which they are avoiding to learn. Teachers 
do not have to wait for the future to be created for them but they themselves need to create the future for the Malaysian education system.

\section{Discussion}

The future challenges for school leaders are not limited to internal factors alone. Being a leader in a learning organization makes the challenges exceed beyond the school environment and the context of education itself. A learning organization requires each of its members, especially the teachers and principals themselves, to learn continuously. Not just that, they should also be able to learn together in order to fulfill the school's vision as a shared desire for the future. Togetherness and learning synergies are essential for a learning organization. Hence, the primary task of learning organization leaders in addressing the challenges discussed is to ensure that teachers can always learn, whether through formal, informal or non-formal means. Most importantly, learning organization leaders must learn how to overcome those challenges.

Internal challenges such as generational diversity and differences offer a wide social network for the learners [6]. Faced with the challenge of generation differences, learning organization leaders need to learn about the advantages of each generation so that each staff's potential can be developed to an optimal level [11]. Limited resources is not the end of any effort. Learning organization leaders need to learn how to optimize the distribution of resources and resource use. The learning leaders should become more creative and innovative [15] in creating and finding more resources. Definitely, a learning organization is a knowledge intensive organization (KIO). There is an abundance of knowledge gained from the learning activities. But, managing the fast increasing knowledge is not an easy task especially in capturing tacit knowledge from individual expert teachers. In managing all types of explicit and tacit knowledge in schools, learning organization leaders need to comprehensively learn and master the skills to manage knowledge using knowledge management tools and appropriate methods. On the other hand, they also need to overcome the challenge of delaying results. Sometimes, learning is a slow process. Leaders in learning organizations should know why they cannot ask for fast results. Learning organization leaders need to equip themselves with knowledge and confidence to answer the problems and concerns posed by the stakeholders because of the delayed results.

External challenges are the challenges that cannot be overcome easily as it involves various intractable factors. Therefore, the best action taken by learning organization leaders as suggested by Pan, Nyeu and Cheng [12] is to encourage and support teachers to further enhance their professionalism, build integrity, develop their own potential by continuously learning, and constantly innovate throughout the learning process. In this way learning organization leaders can ensure that they have the best quality staff and are able to serve well wherever they are.

The study found seven future challenges in the leadership of learning organizations. These challenges have been classified into two main categories, namely internal challenges and external challenges. Internal challenges are referred to as challenges in a particular school. Internal challenges are easy to handle if school leaders have good 
and effective leadership skills. External challenges refer to the challenges that come from outside of the school. These challenges are more difficult to predict as it is difficult to anticipate the results from chains of interaction between schools with diverse environments.

\section{$7 \quad$ References}

[1] Bertoli, B., Giachino, C., Rossotto, C., \& Bitbol-Saba, N. (2018). The role of a knowledge leader in a changing organizational environment. A conceptual framework drawn by an analysis of four large companies. Journal of Knowledge Management, 22 (3), 587-602. https://doi.org/10.1108/jkm-09-2017-0422

[2] Bhengu, T., \& Gounder, R. (2014). School Leadership Role in Creating a Learning Organisation: Perspectives from the Primary School Teachers and School Management. International Journal of Educational Sciences, 7(3), 633-642. https://doi.org/10.1080/09 751122.2014.11890225

[3] Chitpin, S. (2014). Principals and the professional learning community: learning to mobilize knowledge. International Journal of Educational Management, 28(2), 215-229. https://doi.org/10.1108/ijem-04-2013-0044

[4] Heaton, D (2017). Consciousness development for the learning organization. The Learning Organization. 24(6), 401-407. https://doi.org/10.1108/tlo-03-2017-0029

[5] Ibrahim, M.S., \& Abdul Wahab, J. L (2012). Education Leadership. Bangi: Universiti Kebangsaan Malaysia Press.

[6] Kaminska, R., \& Borzillo, S. (2018). Challenges to the learning organization in the context of generational diversity and social networks. The Learning Organization, .25(2), 92-101. https://doi.org/10.1108/tlo-03-2017-0033

[7] Lakomski, G. (2001). Organizational change, leadership and learning: culture as cognitive process. The International Journal of Educational Management, 15(2), 68-77. https://doi.org/10.1108/09513540110383791

[8] Muhammad Siddique, C. (2017). National culture and the learning organization: A reflective study of the learning organization concept in a non-Western country, Management Research Review, 40(2), 142-164. https://doi.org/10.1108/mrr-04-2015-0091

[9] Newman, N., \& Newman, D. (2015). Learning and knowledge: a dream or nightmare for employees. The Learning Organization, 22(1), 58 - 71. https://doi.org/10.1108/tlo-02-2013$\underline{0002}$

[10] Ohlsson, J. (2014). Pedagogic challenges in the learning organization. The Learning Organization, 21(3), 162-174. https://doi.org/10.1108/tlo-09-2013-0045

[11] Orlando, J. (2014). Teachers' changing practices with information and communication technologies: an up-close, longitudinal analysis. Research in Learning Technology, 22(1), https://doi.org/10.3402/rlt.v22.21354

[12] Pan, W.H., Nyeu, F., \& Cheng, S. (2017). Leading school for learning: principal practices in Taiwan. Journal of Educational Administration, 55(2), 68-185. https://doi.org/10.11 08/jea-06-2016-0069

[13] Phillips, B.T (2003). A four-level learning organization benchmark implementation model. The Learning Organization, 10(2), 98-105. https://doi.org/10.1108/09696470910462102

[14] Qiu, S. L. (2010). The New Practices of the Learning Organization. Beijing: China Machine Press. 
[15] Reissner, S. C. (2005). Learning and innovation: a narrative analysis. Journal of Organizational Change Management, 18(5), p.482 - 494. https://doi.org/10.1108/0 9534810510614968

[16] Retna, K. S., \& Ng, P. T. (2006). The challenges of adopting the learning organization philosophy in a Singapore school. International Journal of Educational Management, 20(2), $140-152$.

[17] Voulalas Z. D., \& Sharpe, F. G. (2005). Creating schools as learning communities: obstacles and processes. Journal of Educational Administration, 43(2), 187-208. https://doi.org/10.11 $\underline{08 / 09578230510586588}$

[18] Wen, H. (2014). The nature, characteristics and ten strategies of learning organization. International Journal of Educational Management, 28(3), 289-298.

\section{Author}

Rosnah Ishak is a senior lecturer at Education Management Department, Faculty of Management and Economics, Sultan Idris Education University, Tanjung Malim, Perak, Malaysia. Her academic interest areas are learning organization, knowledge management, leadership communication with contemporary research methods such as Delphi and Fuzzy Delphi. She is a teacher by practice for more than twenty years. Her articles were published in English and Malay language. She published three books with a leading publisher in Malaysia.

Article submitted 2019-12-06. Resubmitted 2020-02-03. Final acceptance 2020-02-07. Final version published as submitted by the authors. 